\title{
REMOVAL OF LEAD(II) IONS FROM AQUEOUS SOLUTIONS USING CASHEW NUT SHELL LIQUID-TEMPLATED THIOL-SILICA MATERIALS
}

\author{
J.E.G. Mdoe ${ }^{1 *}$ and J.S.M. Makene ${ }^{2}$ \\ ${ }^{1}$ Department of Chemistry, University of Dar es Salaam, P. O. Box 35061, Dar es Salaam, \\ Tanzania \\ ${ }^{2}$ Tanzania Bureau of Standards, P. O. Box 9524, Dar es Salaam, Tanzania
}

(Received April 19, 2013; revised April 28, 2014)

\begin{abstract}
A range of thiol-silica composites were prepared using cashew nut shell liquid (CNSL) or one of its phenolic constituents, cardanol, as templates. The procedure involved formation of a CNSL or cardanol emulsion in a water-ethanol system into which (3-mercaptopropyl)-trimethoxysilane and tetraethyl orthosilicate were simultaneously added at various ratios. The reaction mixture was aged at room temperature for $18 \mathrm{~h}$ followed by a Soxhlet extraction of the template and drying. The materials were characterized by diffuse reflectance Fourier transform infrared, nitrogen physisorption, scanning electron microscopy and acid titration. Results indicated that indeed the thiol-silica composites were successfully prepared, with thiol group loadings ranging from 1.6-2.5 $\mathrm{mmol} / \mathrm{g}$. The materials were tested for lead(II) adsorption, and results showed that they had maximum adsorption capacities up to $66.7 \mathrm{mg} / \mathrm{g}$, depending on the thiol group loading and type of template used in preparing the adsorbent
\end{abstract}

KEY WORDS: Thiol-silica materials, Cashew nut shell liquid, Lead(II) adsorption

\section{INTRODUCTION}

Heavy metals pollution represents a significant environmental problem arising from their toxic effects and accumulation in the food chain [1]. Their excessive use and their tendency for nonbiodegradability often lead to their accumulation in water bodies, and subsequent bioaccumulation in aquatic fauna and biota [2]. Lead is one of the potentially toxic heavy metals causing anaemia, paralysis, coma, kidney dysfunctions, brain damage, bone diseases, skin and lung cancer, convulsion and even death if ingested at elevated levels. It is highly toxic especially when its concentration exceeds the threshold limit value (15 ppb) in drinking water, which is the major source of exposure by the general population [3]. High blood lead levels are associated with delayed puberty in girls and lead is also harmful for women's ability to reproduce. It is, therefore, necessary to reduce the level of lead in effluents before discharging into water bodies. Several processes such as adsorption, ion exchange, precipitation, ultrafiltration or reverse osmosis have been used for removing heavy metal ions from aqueous media [4-6]. Of all these, adsorption has proved to be one of the most feasible, simple, selective, cost-effective, ease to operate, and high-efficient process for the removal of heavy metals from polluted water sources. Many adsorbents have been used for the adsorption process. Unfortunately, the adsorbents have their own inherent challenges that include wide distribution of pore size, heterogeneous pore structure, low selectivity, heterogeneous reactions and relatively low metal loading capacities [7]. It is therefore imperative that the search for a cost-effective adsorbent continues.

Highly ordered mesoporous silicas developed via a templating route falls under a class of materials discovered in the early 1990s by Mobil researchers [8]. The materials have unique large surface areas, well-defined pore sizes and structures, potential of surface modification and controllable surface reactivity [9], properties that have attracted a great attention. The tendency for the materials to undergo surface modification using various organic functional groups has boosted their physical and chemical properties and hence their applications [10]. The chemical

*Corresponding author. E-mail: james_mdoe@yahoo.co.uk 
surface modification of the mesoporous silica materials to introduce organic moieties such as vinyl groups, alcohols, thiols, sulfonic and carboxylic acids and amines has always been achieved by either of three pathways [11]: (i) through a reaction between organosilanes or organic molecules and silica surface functions, (ii) chlorination of the silica surface followed by reaction of the $\mathrm{Si}-\mathrm{Cl}$ with an appropriate functional molecule, and (iii) incorporation of functional groups via sol-gel methodology followed by (where necessary) post-modification. The first and second methods involve a post-modification of preformed silica (grafting) whereas the third is a simultaneous co-condensation of corresponding silica and organic group precursors in the presence of a template [12]. Upon solvent extraction of the template, a composite material is obtained. Since the organic functionalities are direct components of the silica matrix, pore blocking is not a problem in the co-condensation method. Furthermore, the organic units are generally more homogeneously distributed than in materials synthesized using the grafting process [13].

Organically functionalized mesoporous silicas are promising adsorbents with high adsorption capacity for heavy metal ions [7, 14-19]. The adsorption mechanism for the removal of the heavy metal ions in an aqueous solution is either by electrostatic interaction or by chelation $[17,20]$. However, for an efficient mass transfer of the adsorbate, pore sizes must be large enough. The pore size is usually a function of the template used. In a different study preparation of an amino-functionalized mesoporous silica with pore diameters up to $24 \mathrm{~nm}$ using CNSL as a template was reported [21]. CNSL is a natural material extracted from cashew nuts of Anacardium occidentale L. plant, a cashew plant grown widely in the tropical region. Solvent extracted CNSL mainly contains anacardic acid and cardanol [22] (Figure 1). The amino-functionalised silica materials were used successfully for the immobilization of invertase enzyme [23]. In the present work, preparation of CNSL-templated thiol-silica composites and their application on the adsorption of lead ions from aqueous solution was studied.

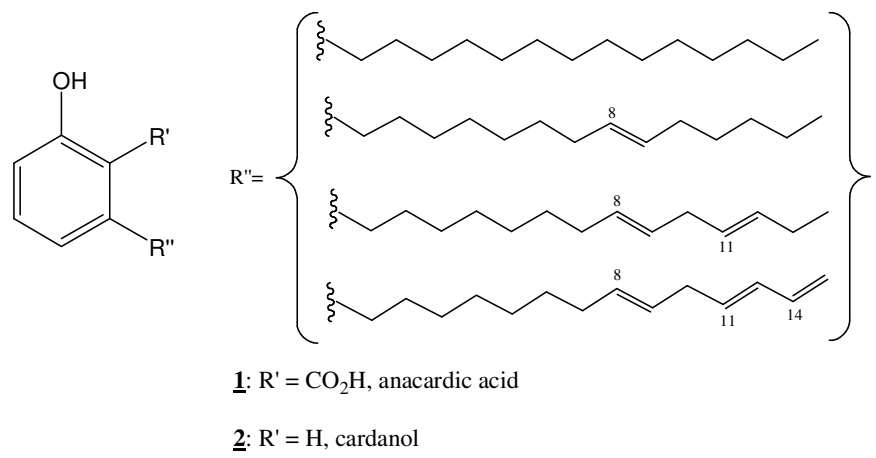

Figure 1. Major components of cashew nut shell liquid.

\section{EXPERIMENTAL}

\section{Materials and reagents}

Chemicals such as, tetraethyl orthosilicate, TEOS, (assay $\geq 98 \%$ ), $n$-dodecylamine (assay 98\%) and (3-mercaptopropyl)-trimethoxysilane, MPTMS, (assay $\geq 98 \%$ ), were purchased from Fluka Chemie. Other standard laboratory grade reagents and chemicals were purchased from Aldrich. All the chemicals were used as received without further purification. In addition, cashew nut shell liquid (CNSL) was extracted from cashew nut shells that were collected from Mtwara region in Tanzania. 
Extraction of cashew nut shell liquid (CNSL)

The CNSL was extracted by soaking cashew nut shells in petroleum ether for three days. A darkish-brownish oil was obtained. The oil was concentrated using a rotary evaporator (model Buchi R-205) at about $40{ }^{\circ} \mathrm{C}$.

Isolation and decarboxylation of anacardic acid

Isolation of anacardic acid from CNSL was done using a procedure reported by Paramashivappa et al. [22]. The procedure involved dissolving natural crude CNSL (150 g) in 5\% aqueous methanol $(400 \mathrm{~mL})$ followed by reacting with $\mathrm{Ca}(\mathrm{OH})_{2}(170 \mathrm{~g})$ slurred in $5 \%$ aqueous methanol $(350 \mathrm{~mL})$ at $40{ }^{\circ} \mathrm{C}$ for $3 \mathrm{~h}$. The obtained calcium anacardate cake was vacuum-filtered and washed thoroughly with $5 \%$ aqueous methanol. The wet calcium anacardate was suspended in distilled water $(450 \mathrm{~mL})$ and $11 \mathrm{M} \mathrm{HCl}(60 \mathrm{~mL})$ and stirred for $1 \mathrm{~h}$. The resultant solution was extracted with ethyl acetate $(2 \times 150 \mathrm{~mL})$. The combined organic layer was washed with distilled water $(3 \times 100 \mathrm{~mL})$, dried over anhydrous sodium sulfate and then filtered and concentrated under reduced pressure at $40{ }^{\circ} \mathrm{C}$ by a rotary evaporator. Thereafter the isolated anarcadic acid was decarboxylated by heating in a furnace at $180-200{ }^{\circ} \mathrm{C}$ for $4 \mathrm{~h}$ to achieve cardanol (Figure 2). The decarboxylation was confirmed by Fourier transform infrared (FTIR) spectroscopy.

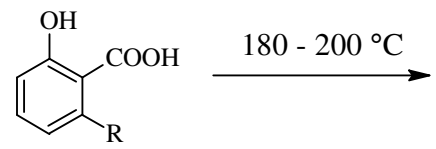

anacardic acid



cardanol

Figure 2. Decarboxylation of anacardic acid.

Synthesis of thiol-silica composites

The synthesis of thiol-silica composites (TSC) was done via a co-condensation of TEOS and MPTMS at various ratios. Different surfactants, namely, CNSL, cardanol or $n$-dodecylamine (DDA) were used as structure directors. $n$-Dodecylamine is a commercial surfactant which has been used before in preparing amino-functionalised silica composites [12]. The synthesis was done as per a procedure outlined elsewhere [24], with some modifications. A typical example of the method is summarized as follows: to a stirred solution of $2.5 \mathrm{~g} \mathrm{CNSL}$ or cardanol, in aqueous ethanol ( $46 \mathrm{~mL}$ of absolute ethanol and $53 \mathrm{~mL}$ of distilled water) at room temperature were added separately, but simultaneously, $1.9 \mathrm{~g}$ MPTMS and $18.4 \mathrm{~g}$ TEOS. After $30 \mathrm{~min}$ of stirring, $0.1 \mathrm{~g}$ of $\mathrm{NaF}$ was added so as to catalyse the condensation reaction and the mixture was further stirred for $18 \mathrm{~h}$. The resulting thick brownish solution was filtered and air-dried for $24 \mathrm{~h}$, followed by template removal from the as-made mesostructure. The extraction was done using ethanol in a Soxhlet apparatus. The ethanol extracted product was then dried in an oven at 100 ${ }^{\circ} \mathrm{C}$ for $10 \mathrm{~h}$ before use. Table 1 shows the identities of the ingredients and the acronyms of the prepared composites.

\section{Characterization of the thiol-silica composites}

The porosity characteristics of the thiol-silica composites were measured by nitrogen adsorption isotherm at $77 \mathrm{~K}$ using an ASAP 2020 Micromeritics instrument. Scanning electron microscopy (SEM) using a ZEISS DSM-950 operated at $5.0 \mathrm{kV}$ was used to study the surface morphologies 
of the materials. A Perkin-Elmer 2000 FTIR spectrophotometer was also employed to confirm the attachment of the thiol functional groups on the silica surfaces. The spectra were recorded from 4000 to $600 \mathrm{~cm}^{-1}$. Furthermore, the amount of thiol functional groups incorporated onto mesoporous silica surfaces during the co-condensation of TEOS and MPTMS (i.e. loading) was determined by an acid titration method. The amount of surface bound species is equivalent to the amount of $\mathrm{HCl}$ acid consumed.

Table 1. Identities of the ingredients and the acronyms of the prepared composites.

\begin{tabular}{|l|c|l|}
\hline Template used & MPTMS:TEOS ratio & Composite acronym \\
\hline Cardanol & $1: 9$ & $1: 9$ MPTMS:TEOS(CAR) \\
\hline Cardanol & $1: 4$ & $1: 4$ MPTMS:TEOS(CAR) \\
\hline CNSL & $1: 9$ & $1: 9$ MPTMS:TEOS(CNSL) \\
\hline CNSL & $1: 4$ & $1: 4$ MPTMS:TEOS(CNSL) \\
\hline$n$-Dodecylamine & $1: 9$ & $1: 9$ MPTMS:TEOS(DDA) \\
\hline$n$-Dodecylamine & $1: 4$ & $1: 4$ MPTMS:TEOS(DDA) \\
\hline
\end{tabular}

\section{Lead(II) adsorption experiments}

Lead(II) adsorption isotherms were obtained using a batch equilibration procedure. Duplicate $0.1 \mathrm{~g}$ adsorbent samples were equilibrated for $3 \mathrm{~h}$ with $50 \mathrm{~mL}$ of aqueous solutions of $\mathrm{Pb}\left(\mathrm{NO}_{3}\right)_{2}$ with metal concentrations ranging from 10 to $80 \mathrm{mg} / \mathrm{L}$. The $\mathrm{pH}$ values of the test solutions were maintained at $\mathrm{pH} 4.0$ by using sodium acetate/acetic acid buffer, a $\mathrm{pH}$ that was well below the precipitation level of lead $(\mathrm{pH}>6.5)$. After equilibration the content of each flask were filtered through a Whatman No. 50 filter paper, and the filtrate analyzed for $\mathrm{Pb}$ (II) ion concentration using atomic absorption spectrophotometer (novAA 400, Analytic Jena AG).

\section{RESULTS AND DISCUSSION}

Synthesis and characterization of thiol-silica composites

The synthesis of thiol-silica composites by a non-electrostatic surfactant assembly was successfully done by a one-pot co-condensation of tetraethyl orthosilicate, a silica source, and (3-mercaptopropyl)-trimethoxysilane. The non-electrostatic templates used in this study were CNSL, cardanol or $n$-dodecylamine. The removal of the templates was easy and complete after a few hours of Soxhlet extraction.

Analysis of the composites by diffuse reflectance Fourier transform infrared (FTIR) showed that indeed the thiol groups were present in the frameworks of the composites as exemplified by Figure 3. In the figure, a weak band at $2600-2550 \mathrm{~cm}^{-1}$ attributable to S-H stretch and strong bands at $2925-2854 \mathrm{~cm}^{-1}$ and $1437 \mathrm{~cm}^{-1}$ attributable to $\mathrm{C}-\mathrm{H}$ stretching and bending vibrations, respectively, were evident [25]. In addition, the typical Si-O-Si bands around $1100 \mathrm{~cm}^{-1}$ and 807 $\mathrm{cm}^{-1}$ associated with the formation of a condensed silica network were also present.

The loading of thiol groups on the surfaces of the synthesized materials as determined by acid titration method, was found to range from 1.6 to $2.5 \mathrm{mmol}$ per $\mathrm{g}$ silica. The loadings were found to vary based on the MPTMS to TEOS ratios. Generally materials prepared using 1:4 ratio had higher organic content than those prepared at 1:9 ratio. 


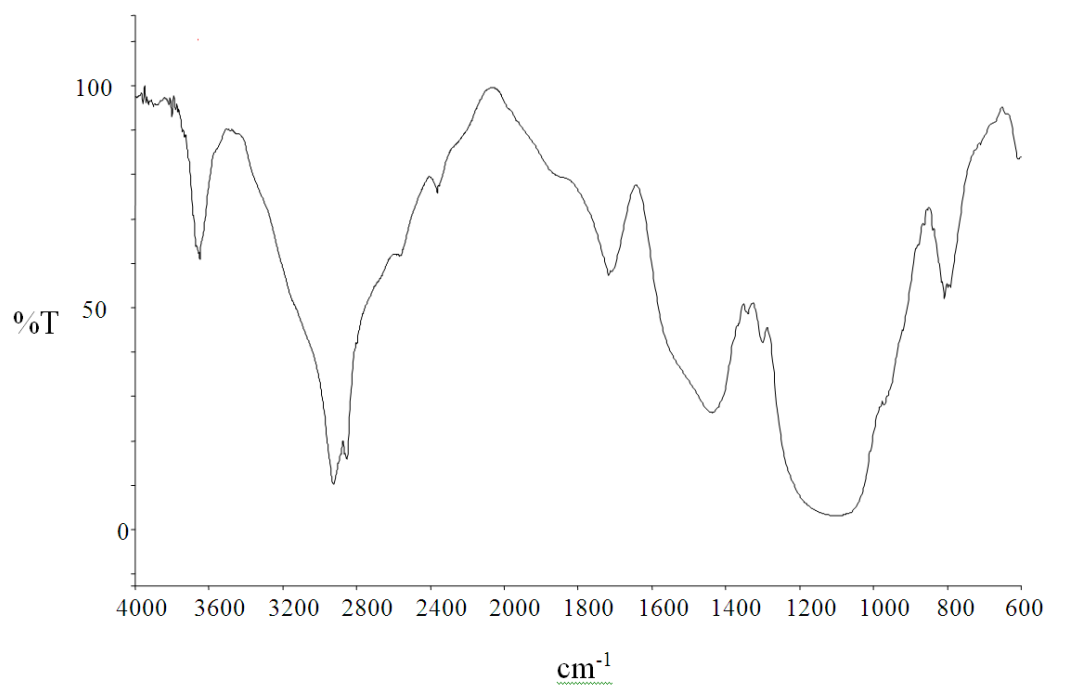

Figure 3. IR spectrum of a typical thiol-silica composite material.

Nitrogen physisorption studies indicated that the prepared materials had type IV isotherms characteristic of mesoporous materials [26]. Typical isotherms are given in Figure 4. It can be seen from the figure that the isotherms form a plateau followed by a sharp rise in nitrogen uptake at a relative pressure of about 0.8 . The sharp rise in nitrogen adsorption at a relative pressure above 0.8 is associated with the formation of a multilayer of adsorbate. The formation of a multilayer causes capillary condensation in the inter-particle pores. The isotherms for CNSL- and cardanol-templated materials showed hysteresis loops at a relative pressure above 0.8. The hysteresis loops are an indirect evidence of mesoporosity, though it may also be due to the wider inter-particle pore size distribution of the materials.

The materials prepared using CNSL or cardanol had surface areas and pore diameters ranging from 176 to $216 \mathrm{~m}^{2} / \mathrm{g}$ and 16 to $19 \mathrm{~nm}$, respectively (Table 2). The pore size analysis was performed by the Barrett, Joyner and Halenda (BJH) model using the desorption branch of the isotherm. A comparison with DDA-templated materials show a remarkable increase in pore dimensions as observed elsewhere in the case of amino-functionalized silica [21]. The differences in pore diameters and surface areas observed between the CNSL/cardanol- and the DDA-templated silicas are attributed to the large phenolic head group in CNSL/cardanol compared to the amine head group found in DDA [23]. Furthermore, there was a consistent decrease in surface areas, pore volumes and pore structures of the CNSL/cardanol-templated silicas as the MPTMS to TEOS ratio increased from 1:9 to 1:4. This suggests that the increased number of thiol groups occupy more space causing steric hindrances and hence a decrease in the porosity parameters.

The morphology for the primary particles of the prepared materials was determined using SEM and representative micrographs are given in Figure 5. As it can be seen, the micrographs for the materials prepared using CNSL templates are comprised of aggregates of roughly spherical and irregularly shaped particles. The latter's typical average size was about $0.5 \mu \mathrm{m}$. The particles for the materials prepared using cardanol as a template were relatively indistinct. They formed clusters of irregularly shaped particles which were mostly amorphous. The sizes of the CNSL-templated materials closely match those reported before for amino-functionalised silica [21]. 


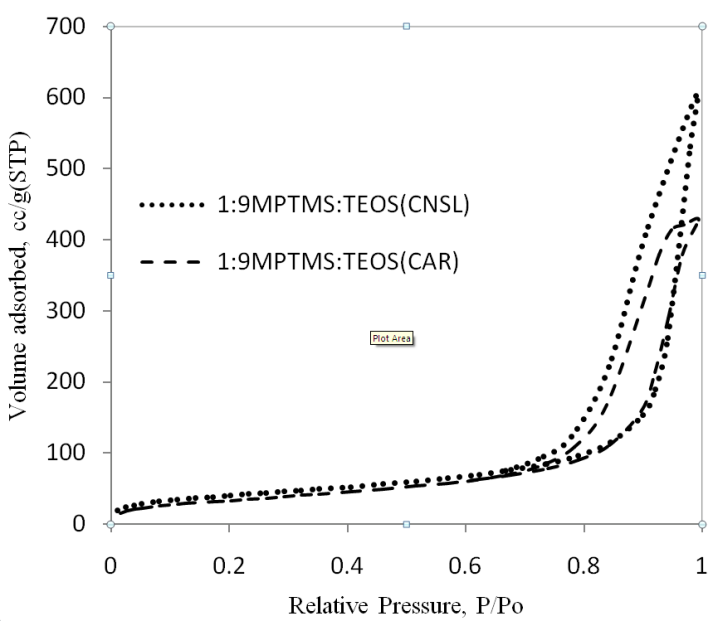

Figure 4. Adsorption-desorption isotherms of the 1:9MPTMS:TEOS(CNSL) and 1:9MPTMS:TEOS(CAR).

Table 2. Results of nitrogen physisorption studies on representative samples of the composites.

\begin{tabular}{|l|c|c|c|}
\hline Material & $\begin{array}{c}\text { Specific surface area (BET)/ } \\
\mathrm{m}^{2} \mathrm{~g}^{-1}\end{array}$ & $\begin{array}{c}\text { Volume of pores } \\
\left(\mathrm{cm}^{3} / \mathrm{g}\right)\end{array}$ & $\begin{array}{c}\text { Mean pore } \\
\text { dia }\end{array}$ \\
\hline 1:9MPTMS:TEOS(CAR) & 192.4 & 0.98 & 15.6 \\
\hline 1:4MPTMS:TEOS (CAR) & 187.2 & 0.76 & 14.3 \\
\hline 1:9MPTMS:TEOS(CNSL) & 216.3 & 1.20 & 18.7 \\
\hline 1:4MPTMS:TEOS(CNSL) & 176.2 & 0.19 & 8.2 \\
\hline 1:9MPTMS:TEOS(DDA)* & 433.6 & 0.24 & 3.1 \\
\hline 1:4MPTMS:TEOS (DDA)* & 358.7 & 0.18 & 3.0 \\
\hline
\end{tabular}

"Used for comparison purposes.
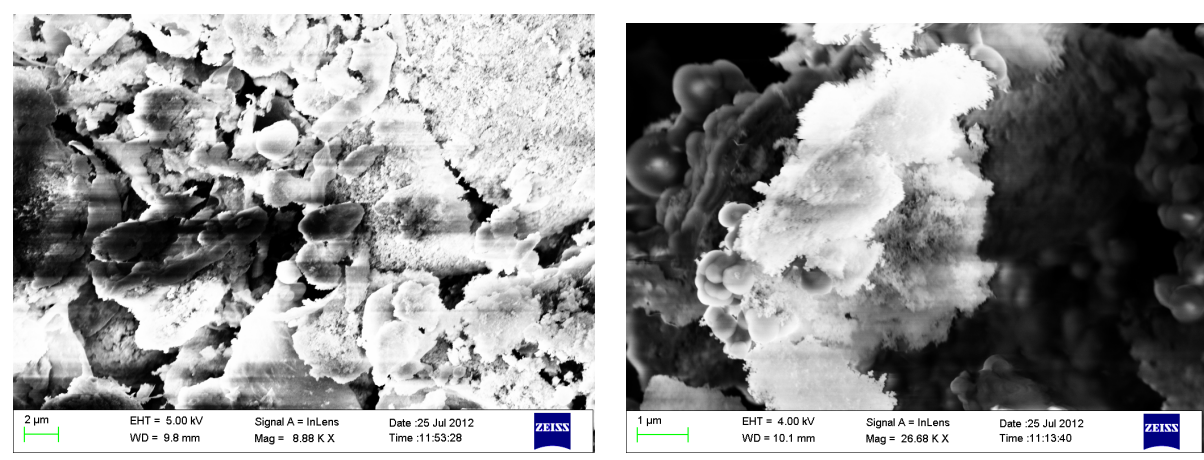

Figure 5. SEM micrographs of a) 1:9MPTSM:TEOS(CAR) and b) 1:9MPTSM:TEOS(CNSL). 
Adsorption of lead (II) on the prepared adsorbents

Lead(II) adsorption capacities on the various thiol-silica materials at different ion concentrations were investigated. The results for $\mathrm{Pb}(\mathrm{II})$ removal from solution at $30^{\circ} \mathrm{C}$ by varying the ion concentration from 10 to $80 \mathrm{mg} / \mathrm{L}$ is shown in Figure 6.

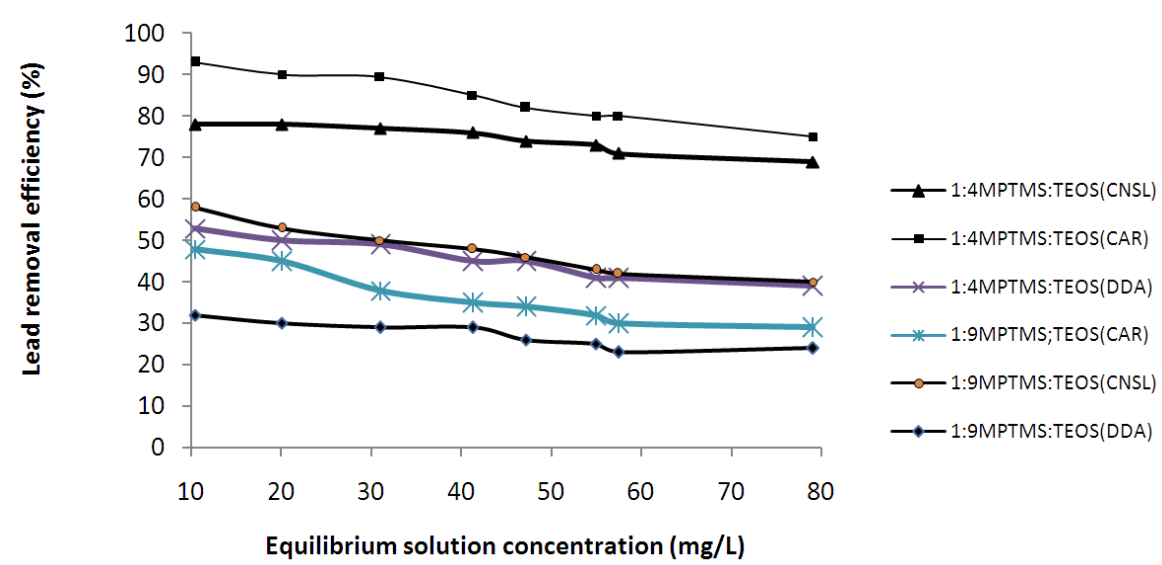

Figure 6. Removal efficiency of $\mathrm{Pb}(\mathrm{II})$ ions according to initial concentration.

As seen from Figure 6 the removal efficiencies for $\mathrm{Pb}(\mathrm{II})$ on all adsorbents decreased with increasing metal ion concentration. The removal efficiency also varied from one adsorbent to another. The lead adsorption efficiencies on the thiol-silica composites prepared at MPTMS to TEOS ratio of 1:4 were higher than those observed on their counterparts prepared at 1:9 ratios, an observation that is attributed to the higher loadings of thiol. Furthermore, the adsorption efficiency varied depending on the template used. The plots show that, TSC materials synthesized using cardanol or CNSL as structure directors are much more efficient in adsorbing $\mathrm{Pb}$ (II) compared to DDA-templated materials. The trend reflects differences in the porosity characteristics as described before for the synthesized materials. Materials synthesized using cardanol or CNSL as structure directors have larger pores and could therefore adsorb metal ions efficiently than DDA-templated materials. Variation in physical properties based on template is in agreement with Hilonga et al. [21].

The distribution of divalent cations between the aqueous phase and the adsorbent is a measure of the equilibrium condition in the adsorption process and can generally be expressed in terms of the Langmuir isotherm. Figure 7 represents the Langmuir adsorption isotherms for the TSC materials. The obtained data were correlated with a linearised form of the Langmuir equation (1), and a typical example of the plots is given in Figure 8.

$\frac{1}{X}=\left(\frac{1}{K_{a} q_{m}}\right) \frac{1}{C}+\frac{1}{q_{m}}$

where, $X$ is the equilibrium sorbate concentration on the adsorbent $(\mathrm{mg} / \mathrm{g}), q_{\mathrm{m}}$ is the maximum adsorption capacity $\left(\mathrm{mg} / \mathrm{g}\right.$ ) and $K_{\mathrm{a}}$ is the equilibrium constant related to the energy of adsorption (L/mg). Fitting by the least-squares method yielded $K_{\mathrm{a}}$ and $q_{\mathrm{m}}$ values which are summarized in Table 3. As expected, the maximum adsorption capacity $\left(q_{\mathrm{m}}\right)$ increased with increase in thiol loading, a trend that is also reported by Thu et al. [18]. This trend is much clearer when comparing materials prepared using the same template. For instance, 1:4 MPTS:TEOS(CNSL) which has a thiol group loading of $2.5 \mathrm{mmol} / \mathrm{g}$ has a maximum adsorption capacity of $66.7 \mathrm{mg} / \mathrm{g}$ 
whereas 1:9 MPTS:TEOS(CNSL) with a loading of $1.6 \mathrm{mmol} / \mathrm{g}$ has an adsorption capacity of $22.5 \mathrm{mg} / \mathrm{g}$.

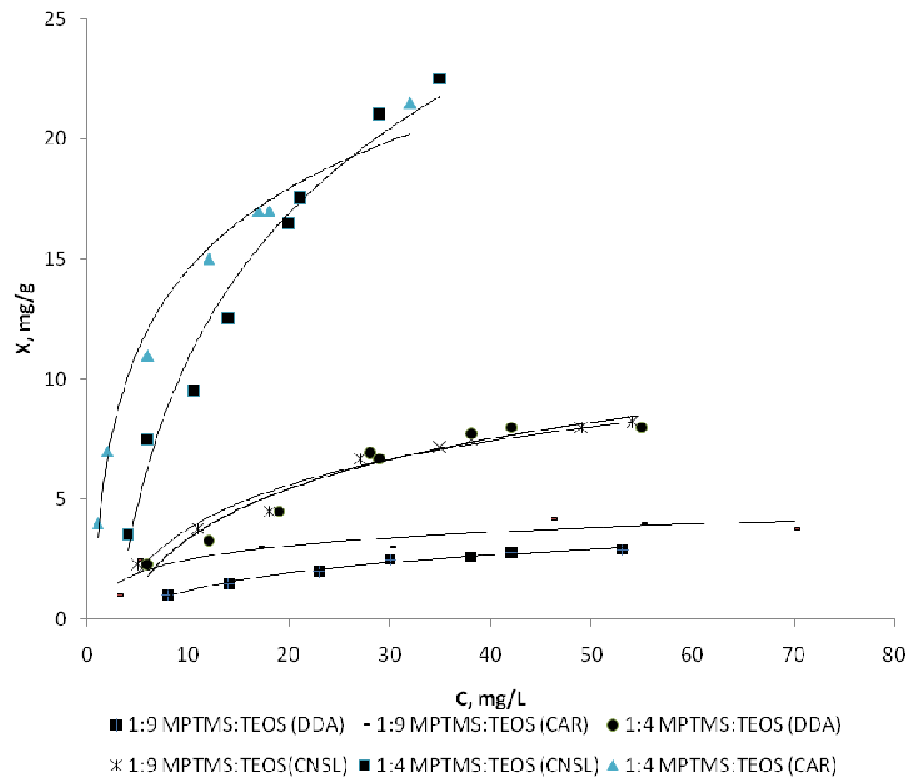

Figure 7. Equilibrium adsorption isotherms for lead onto TSC materials.

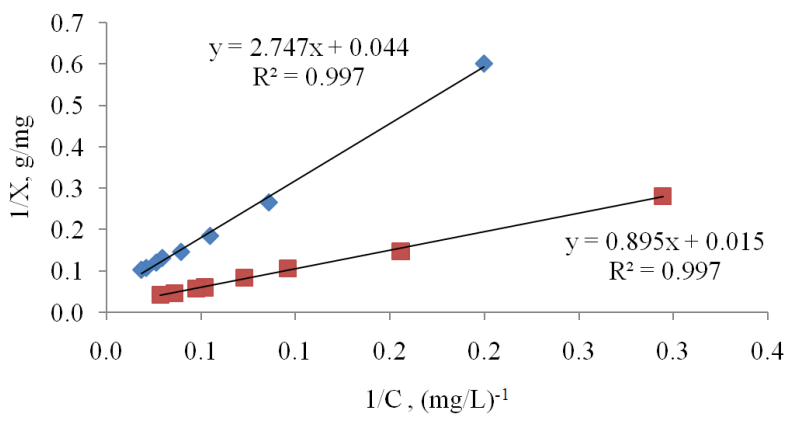

1:9 MPTMS: TEOS(CNSL) $\quad$ 1:4 MPTMS: TEOS (CNSL)

Figure 8. Langmuir plot for lead adsorption onto TSC prepared using CNSL as structure director.

Table 3. Thiol groups loading and Langmuir and Freundlich parameters of metal ion adsorption on the prepared adsorbents.

\begin{tabular}{|l|c|c|c|c|c|c|c|}
\hline Composite & Loading $\left(\mathrm{mmol} \mathrm{g}^{-1}\right)$ & \multicolumn{3}{|c|}{ Langmuir } & \multicolumn{3}{c|}{ Freundlich } \\
\cline { 3 - 8 } & & $\mathrm{q}_{\mathrm{m}}(\mathrm{mg} / \mathrm{g})$ & $k$ & $\mathrm{R}^{2}$ & $\mathrm{k}$ & $1 / \mathrm{n}$ & $\mathrm{R}^{2}$ \\
\hline 1:4MPTMS:TEOS (CAR) & 2.5 & 53.8 & 0.10 & 0.998 & 1.46 & 0.51 & 0.971 \\
\hline 1:9MPTMS:TEOS (CAR) & 1.7 & 6.2 & 0.07 & 0.992 & 0.59 & 0.56 & 0.959 \\
\hline 1:4MPTMS:TEOS (CNSL) & 2.5 & 66.7 & 0.02 & 0.998 & 1.39 & 0.82 & 0.903 \\
\hline 1:9MPTMS:TEOS (CNSL) & 2.0 & 22.7 & 0.02 & 0.997 & 0.59 & 1.05 & 0.732 \\
\hline 1:4MPTMS:TEOS (DDA) & 2.2 & 21.3 & 0.02 & 0.999 & 1.81 & 0.73 & 0.970 \\
\hline 1:9MPTMS:TEOS (DDA) & 1.6 & 6.5 & 0.02 & 0.999 & 0.26 & 0.56 & 0.975 \\
\hline
\end{tabular}

Bull. Chem. Soc. Ethiop. 2014, 28(3) 
Generally, the Langmuir equation effectively described the adsorption data with all $\mathrm{R}^{2}$ values being $\geq 0.99$. The good correlation of the adsorption data by the equation indicates that the $\mathrm{Pb}$ (II) adsorption behavior on the prepared materials was mostly restricted to monolayer adsorption. This is also in line with the gradual decrease in the percentage of lead(II) ions removed from the solution as the initial concentration was increased (Figure 6).

The Freundlich adsorption model was also applied to the adsorption of the $\mathrm{Pb}$ (II). Results from plots of the linearised Freundlich equation (2) indicated that $\mathrm{R}^{2}$ values ranged from 0.73 to 0.97. The relatively low correlation of the Freundlich equation over the Langmuir equation proves further that the adsorption process is mainly monolayer. The equation was also used to calculate the constants $k$ and $1 / \mathrm{n}$ which are given in Table 3 .

$\log X=\log k+\left(\frac{1}{\mathrm{n}}\right) \log C$

The coefficient $k$ is a parameter that reflects the amount of the active adsorption site whereas $1 / \mathrm{n}$ is a characteristic coefficient related to energy or intensity of adsorption [27]. As seen in Table 3 , materials with high loadings correspondingly show large values of $k$. However, this is only seen when materials made using the same template are compared. If the comparison is extended to materials made using different templates, the trend is not very apparent. This might be attributed to differences in pore structure as a result of the differences in templating, hence affecting accessibility of the active sites by the metal ions.

The obtained adsorption capacities of the synthesized thiol-silica composites were compared to previously reported works on adsorption capacities of $\mathrm{Pb}$ (II) ions by different thiol functionalized mesoporous silicas synthesized by co-condensation at various MPTMS to TEOS ratios (Table 4). The table shows that the experimental data of the present study are comparable to many corresponding adsorbents despite the use of different templating agents. Whereas CNSL and cardanol were used in this work as templates, P123 $\left(\mathrm{HO}\left(\mathrm{CH}_{2} \mathrm{CH}_{2} \mathrm{O}\right)_{20}\left(\mathrm{CH}_{2} \mathrm{CH}\left(\mathrm{CH}_{3}\right) \mathrm{O}\right)_{70}\left(\mathrm{CH}_{2} \mathrm{CH}_{2} \mathrm{O}\right)_{20} \mathrm{H}\right)$ was used in Hoang et al. [15] and Thu et al. [18].

Table 4. Comparative analysis of $\mathrm{Pb}^{2+}$ adsorption on different propylthiol functionalized mesoporous silica.

\begin{tabular}{|c|c|c|c|}
\hline Adsorbent & $\begin{array}{l}\text { MPTMS/TEOS } \\
\text { ratio }\end{array}$ & $\begin{array}{c}\mathrm{Pb} \text { (II) adsorption capacity } \\
(\mathrm{mg} / \mathrm{g})\end{array}$ & Ref. \\
\hline HS-SBA-15-30(0.121) & 1:8 & 64.8 & {$[15]$} \\
\hline HS-SBA-15-30(0.174) & $1: 6$ & 105.3 & {$[15]$} \\
\hline SBA-15/SH-5 & 5: 100 & 16.6 & [18] \\
\hline SBA-15/SH-10 & 10: 100 & 22.8 & [18] \\
\hline SBA-15/SH-15 & 15: 100 & 26.9 & {$[18]$} \\
\hline SBA-15/SH-20 & $20: 100$ & 31.1 & {$[18]$} \\
\hline SBA-15/SH-30 & $30: 100$ & 39.4 & {$[18]$} \\
\hline 1:4MPTMS:TEOS(CAR) & $1: 4$ & 53.8 & This work \\
\hline 1:9MPTMS:TEOS(CAR) & $1: 9$ & 6.2 & This work \\
\hline 1:4MPTMS:TEOS(CNSL) & $1: 4$ & 66.7 & This work \\
\hline 1:9MPTMS:TEOS(CNSL) & $1: 9$ & 22.7 & This work \\
\hline
\end{tabular}

\section{CONCLUSION}

Thiol-silica composites were successfully synthesized by co-condensation of silica and thiol group precursors on CNSL or cardanol, as templates. The materials prepared using CNSL or cardanol templates had surface areas ranging from 176 to $216 \mathrm{~m}^{2} / \mathrm{g}$ and pore diameters up to 19 $\mathrm{nm}$. Results on of $\mathrm{Pb}$ (II) ions adsorption from aqueous solution indicated that equilibrium was reached within $3 \mathrm{~h}$. The adsorption data fitted very well the Langmuir isotherm relative to the 
Freundlich isotherm model, indicating monolayer adsorption. The obtained maximum adsorption capacity was $66.7 \mathrm{mg} \mathrm{Pb}$ (II) per g adsorbent which was comparable to other reported materials. However, the materials developed in this study are relatively cheaper than most commercial adsorbents because the templates used to prepare them are cheaply available as byproducts in cashew nut processing industries. Hence they may compete favourably with many commercial adsorbents.

\section{ACKNOWLEDGEMENTS}

The authors would like to thank Tanzania Bureau of Standards (TBS) and the University of Dar es Salaam for financial and logistical support, respectively.

\section{REFERENCES}

1. Vimala, R.; Das, N. J. Hazard. Mater. 2009, 168, 376.

2. Larbi, E.H.; Laghzizil, A.; Saoiabi, A.; Barboux, P.; Meyer, M.; Brandes, S.; Guilard, R. Adsorpt. Sci. Technol. 2006, 24, 507.

3. Mustafaa, S.; Tasleemb, S.; Naeema, A.; Safdar, M. Colloids Surf. 2008, A 330, 8.

4. Chiron, N.; Guilet, R.; Deydier, E. Water Res. 2003, 37, 3079.

5. Kryvoruchko, A.P.; Atamanenko, I.D.; Yurlova, L.Y. J. Membr. Sci. 2004, 228, 77.

6. Qdais, H.A.; Moussa, H. Desalination 2004, 164, 105.

7. Park, J.; Kim, H.; Park, J. Int. J. Environ. Sci. Technol. 2012, 3, 81.

8. Kresge, C.T.; Leonowicz, M.E.; Roth, W.J.; Vartuli, J.C.; Beck, J.S. Nature 1992, 359, 710.

9. Stein, A. Adv. Mater. 2003, 15, 763.

10. Liu, D.; Lei, J.H.; Guo, L.P.; Du, X.D.; Zeng, K. Microporous Mesoporous Mater. 2009, 117, 67.

11. Price, P.M.; Clark, J.H.; Macquarrie, D.J. J. Chem. Soc., Dalton Trans. 2000, 2, 101.

12. Macquarrie, D.J. Chem. Commun. 1996, No. 16, 1961.

13. Hoffmann, F.; Cornelius, M.; Morell, J.; Fröba, M. Angew. Chem. Int. Ed. 2006, 45, 3216.

14. Carlos, A.Q.; Victor, S.; Wencel, C.; Gustavo, R.P.; Ricardo, M.; Sergio, G. Chem. Mater. 2009, 21, 1439.

15. Hoang, V.D.; Dang, T.P.; Dinh, Q.K.; Nguyen, H.P.; Vu, A.T. Adv. Nat. Sci.: Nanosci. Nanotechnol. 2010, 1, 035011.

16. Jose, A.; Jesús, M.A.; Amaya, A. Ind. Eng. Chem. Res. 2005, 44, 3665.

17. Quintanilla, D.P.; Hierro, ID.; Fajardo, M. J. Hazard. Mater. 2006, 134, 245.

18. Thu, P.T.T.; Thanh, T.T.; Phi, H.N.; Kim, S.J.; Vo, V. J. Mater. Sci. 2010, 45, 2952.

19. Wu, S.; Li, F.; Xu, R.; Wei, S. J. Nanopart. Res. 2010, 12, 2111.

20. Cestari, A.R.; Vieira, E.F.S.; Vieira, G.S.; Costa, L.P.; Tavares, A.M.G.; Loh, W.; Airoldi, C. J. Hazard. Mater. 2009, 161, 307.

21. Hilonga, A.; Mdoe, J.E.G.; Mkayula, L.L. Int. J. BioChemiPhysics 2009, 17, 26.

22. Paramashivappa, R.; Zolfigol, P.; Kumar, P.; Vithayathil, P.J. Rao, A.S. J. Agric. Food. Chem. 2001, 49, 2548.

23. Mubofu, E.B.; Mdoe, J.E.G.; Kinunda, G. Catal. Sci. Technol. 2011, 1, 1423.

24. Mori, Y.; Pinnavaia, T.J. Chem. Mater. 2001, 13, 2173.

25. Degen, I.A. Tables of Characteristics Group Frequencies for the Interpretation of Infrared and Raman Spectra, Acolyte Publications: Harrow; 1997.

26. Rouquerol, F.; Sing, K. Adsorption by Powders and Porous Solids: Principles Methodology and Applications, Academic Press: London; 1999.

27. Erdem, E.; Karapinar, N.; Donat, R. J. Colloid Interf. Sci. 2004, 280, 309. 